\title{
Pharmacokinetics of Diphenhydramine in Man
}

\author{
Kenneth S. Albert, ${ }^{1}$ Margarette R. Hallmark, ${ }^{2}$ Ermelinda Sakmar, ${ }^{2}$ \\ Donald J. Weidler, ${ }^{2}$ and John G. Wagner ${ }^{2,3}$
}

Received May 9. 1974--Final Jan. 28, 1975

\begin{abstract}
Plasma levels and urinary excretion of diphenhydramine were measured after administration of three single 50-mg doses of diphenhydramine hydrochloride to two healthy male volunteers as an intravenous infusion, an oral solution, and a commercially available capsule. A large first-pass effect was evident from the data, with about $50 \%$ of the drug being metubolized by the liver before it reached the general circulation. The drug in solution given orally appeared to be fully available to the hepatoportal system, and the availability of diphenhydramine from the capsule was about $83 \%$ relative to the solution in one subject and $100 \%$ in the other subject. Cumulative amounts of unchanged diphenhydramine excreted in the urine were less than $4 \%$ of the administered dose. Both subjects went to sleep at the end of the I-hr intravenous infusion, but were only drowsy following the oral treatments.
\end{abstract}

KEY WORDS: diphenhydramine: intravenous infusion; oral administration: first-pass effect ; bioavailability.

\section{INTRODUCTION}

Diphenhydramine hydrochloride, 2-(diphenylmethoxy)- $N, N$-dimethylethylamine hydrochloride, is an effective antihistaminic agent possessing anticholinergic, antitussive, antiemetic, and sedative properties (1). Although the drug has been used clinically for many years, relatively little information

This study was performed pursuant to Contract No. FDA 69-22 with Public Health Service,

Food and Drug Administration, Department of Health, Education, and Welfare, and was supported in part by Public Health Service Grant 5-P11-GM15559.

${ }^{1}$ Present address: Merck Sharp and Dohme Research Laboratories, West Point, Pennsylvania 19486.

${ }^{2}$ College of Pharmacy and Upjohn Center for Clinical Pharmacology, The University of Michigan, Ann Arbor, Michigan 48104.

${ }^{3}$ Address reprint requests to Dr. John G. Wagner, Upjohn Center for Clinical Pharmacology, The University of Michigan, Ann Arbor, Michigan 48104. 
is available on its absorption, distribution, and elimination in man. Hald (2) found that $3 \%$ of a therapeutic dose $(50 \mathrm{or} 100 \mathrm{mg}$ ) of the drug was excreted unchanged in human urine. Glazko et al. (3) administered 50-mg oral doses of diphenhydramine (as its salicylate and hydrochloride salts) twice and four times daily to five subjects for 5 consecutive days. Average peak plasma levels were $84 \pm 30$ and $160 \pm 25 \mathrm{ng} / \mathrm{ml}$, respectively, for the two dose levels (after accumulation had occurred during days 1-5). In addition, an apparent plasma half-life of about $18 \mathrm{hr}$ was reported.

The present pilot study was undertaken to elucidate the pharmacokinetic parameters of diphenhydramine in man after administration of the drug as an intravenous infusion, an oral solution, and a commercially available capsule, and to evaluate its availability from the capsule relative to the solution.

\section{EXPERIMENTAL}

\section{Protocol}

Two healthy adult male volunteers both 27 years of age and weighing 76 and $95 \mathrm{~kg}$, with normal vital signs and laboratory screening values, were selected for the study. Each subject received three single 50-mg doses of diphenhydramine hydrochloride as an intravenous infusion, an oral solution, and a commercially available capsule according to the dosage schedules shown in Table I. Treatments were separated by a 2 -week period. The subjects fasted from $10 \mathrm{hr}$ prior to dosing until $4 \mathrm{hr}$ after administration of the drug. In order to assure hemodynamics similar to that when the drug was given orally, subjects were required to stand periodically during the infusion.

Twenty-milliliter blood samples were collected in citrated Vacutainers just prior to dosing and at the times indicated in Table II. The plasma was separated, frozen, and kept in a frozen state until just prior to assay. Urine specimens were collected in plastic bottles containing $1 \mathrm{ml}$ of toluene for the following time intervals after administration: $0-6,6-24$, and $24-48 \mathrm{hr}$. The volumes were recorded, the urine was acidified with concentrated hydrochloric acid (to back-extract any diphenhydramine that may have partitioned into the toluene layer), and an aliquot was frozen until just prior to assay.

\section{Analytical Method}

Plasma and urine specimens were assayed for diphenhydramine by a GLC procedure shown to be specific for unchanged drug (4). In addition, the contents of the intravenous infusion and oral solution dosage forms were assayed for exact drug content. 
Table I. Dosage Schedules and Treatments

\begin{tabular}{l} 
Subject given treatment \\
$\begin{array}{c}\mathrm{A}^{a} \\
\text { (intravenous } \\
\text { infusion) }\end{array}$ \\
$\begin{array}{c}\text { (oral } \\
\text { solution) }\end{array}$ (capsule) \\
\hline Phase \\
II
\end{tabular}

\section{Determination of Whole Blood/Plasma Distribution Ratio}

Two-milliliter portions of citrated drug-free whole blood from each subject were incubated with tritium-labeled diphenhydramine hydrochloride (specific activity $13.4 \mu \mathrm{Ci} / \mathrm{mg}$, supplied by Parke, Davis and Company) ${ }^{4}$ for $30 \mathrm{~min}$ at $37^{\circ} \mathrm{C}$ using an aqueous stock solution, $11.3 \mu \mathrm{g} / \mathrm{ml}$. Final concentrations of diphenhydramine hydrochloride were 113 and $904 \mathrm{ng} / \mathrm{ml}$. After incubation, the plasma was separated by centrifuging at $2000 \mathrm{rpm}$ for $20 \mathrm{~min}$. The samples were analyzed for radioactivity by adding $100 \mu \mathrm{l}$ of each to $15 \mathrm{ml}$ Unogel (Schwarz/Mann Co.) and counting for $10 \mathrm{~min}$ in a scintillation counter (Packard Tri-Carb liquid scintillation spectrometer). The whole blood/plasma ratio was calculated by comparing the radioactivity of whole blood samples to similarly treated plasma standards containing 113 and $904 \mathrm{ng} / \mathrm{ml}$ of tritiated diphenhydramine hydrochloride.

${ }^{4}$ The sample, recrystallized from a benzene-methanol solution, was shown to be homogeneous by TLC. 


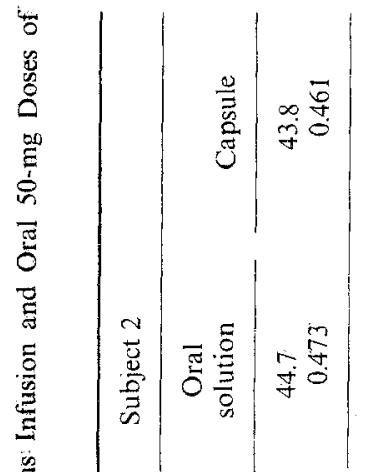

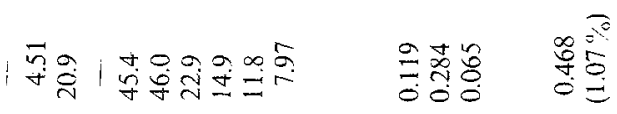

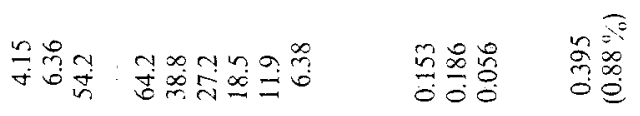

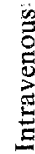

$\stackrel{9}{50}$

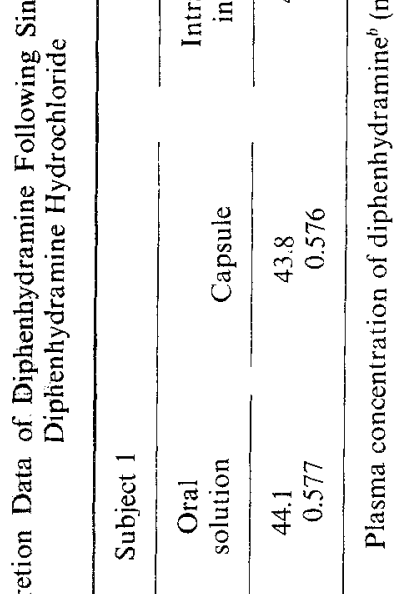

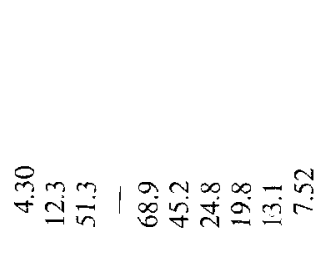

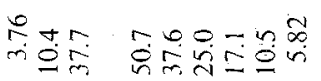

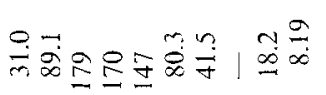

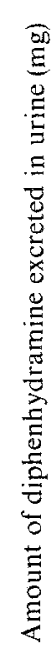

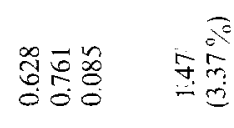

형

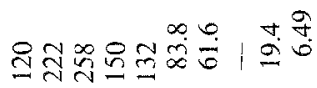

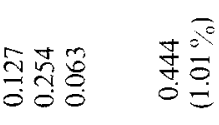

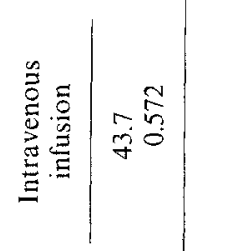

๙ึ่ำ

斗学

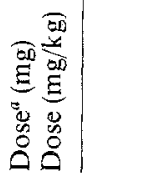

E्छ

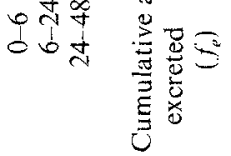

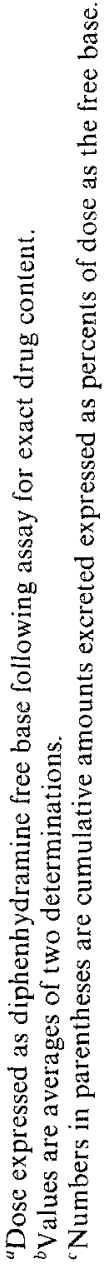




\section{Determination of Plasma Protein Binding}

Two-milliliter portions of drug-free plasma from each subject were incubated for $30 \mathrm{~min}$ at $37^{\circ} \mathrm{C}$ with tritium-labeled diphenhydramine hydrochloride using an aqueous stock solution, $11.3 \mu \mathrm{g} / \mathrm{ml}$. Final concentrations were 113 and $1130 \mathrm{ng} / \mathrm{ml}$.

Ultrafiltration of the plasma samples was performed at $37^{\circ} \mathrm{C}$ in membrane cones (Centrifto CF-50 membrane ultrafilter, Amicon Corp.) which were soaked in deionized water for at least $1 \mathrm{hr}$ before use. After removal of residual water by centrifugation at $1000 \mathrm{~g}$ for $5 \mathrm{~min}, 1.9 \mathrm{ml}$ of plasma was pipetted into the cone, then centrifuged at $800 \mathrm{~g}$ for $30 \mathrm{~min}$. At the end of the centrifugation, 100- $\mu$ l aliquots of ultrafiltrate were removed for scintillation counting as described above. A $100-\mu$ l portion of plasma was analyzed for radioactivity prior to centrifugation. The unbound fraction was calculated as the quotient of the radioactivity in the ultrafiltrate and in the plasma before ultrafiltration.

\section{Data Analysis}

The total area under the plasma concentration-time curve from zero to infinity was estimated for each of the six sets of data by two different methods. One method involved fitting of the concentration-time data to a polyexponential equation using the program AUTOAN (5) and an IBM 360/67 digital computer. The polyexponential equation was then integrated to obtain the area. The program AUTOAN interpolates one plasma concentration-time point between each pair of real points by spline and Akima methods (6). It then calculates every possible polyexponential equation from one to five exponential terms which could describe the data and provides the coefficients and exponents for the optimum number of terms. The criterion used is a moving scale percentage improvement in the sum of squared deviations depending on the value of $r^{2}$ (defined in footnote $b$ to Table III). The other method involved estimating the area from 0 to $24 \mathrm{hr}$ by means of the trapezoidal rule, then estimating the area from $24 \mathrm{hr}$ to infinity by dividing the observed plasma concentration at $24 \mathrm{hr}$ by the $\beta$ value estimated from the $12-$ and 24 -hr plasma concentrations observed following intravenous infusion of the drug.

\section{RESULTS AND DISCUSSION}

Table II summarizes both the plasma concentration and urinary excretion data for subjects 1 and 2 following the three treatments. A first-pass effect ${ }^{5}$ was evident from the data, which showed that the area under the oral

\footnotetext{
${ }^{5}$ The apparent plasma clearances, estimated directly from the intravenous infusion data in Table II as dose/area, were 37.0 liters/hr $[0.48 \mathrm{liter} /(\mathrm{kg} \times \mathrm{hr})]$ for subject 1 and $41.1 \mathrm{liters} / \mathrm{hr}$ $[0.44$ liter $/(\mathrm{kg} \times \mathrm{hr})]$ for subject 2 . These high clearances suggested that diphenhydramine was subject to a frst-pass effect.
} 
solution curve was considerably less than the corresponding area following intravenous administration. The data also revealed that for one subject, but not the others, absorption of diphenhydramine from the commercial capsule was somewhat less than when the drug was administered orally in solution.

Cumulative amount of unchanged diphenhydramine excreted in the urine following the two oral treatments was about $1 \%$ of the administered dose in both subjects, while that for intravenous infusion was about $2 \%$ for subject 1 and $3 \%$ for subject 2 . These low values excluded use of urinary excretion data as reliable measures of absorption efficiency.

\section{Data Analysis}

The polyexponential equations obtained by use of the program AUTOAN are given in Table III. The post-intravenous-infusion data for both subjects were described by a biexponential equation. Three of the four sets of oral data were described by a four-term exponential equation, while the fourth set was described by a five-term polyexponential equation. Although several models could be envisioned which might be appropriate, there is insufficient information in these data to make a judicious choice. Retrospectively, a more intensive plasma sampling scheme both immediately following cessation of the intravenous infusion and beyond the 24-hr time period would be necessary to permit choice of the most appropriate pharmacokinetic model.

The areas estimated by the two different methods are summarized in Table IV. The footnotes to Table IV clearly indicate how the areas were estimated.

\section{Bioavailability Considerations}

\section{First-Pass Effect}

The extent of the first-pass effect on drug bioavailability may be determined by equation 1 :

$$
\theta=\frac{(\text { dose })_{\mathrm{i} . v .} \int_{0}^{\infty} C_{\text {oral }} d t}{(\text { dose })_{\text {oral }} \int_{0}^{\infty} C_{\text {i.v. }} d t}
$$

where $\theta$ represents the fraction of the drug which is administered by the oral route that reaches the general circulation. Rowland (7) has shown that for drugs exhibiting dose-independent kinetics the bioavailability of an oral dose of drug following its first-pass through the liver may be estimated by use of equation 2 :

$$
\theta=1-\frac{f_{m}(\text { dose })_{\text {i.v. }}}{\dot{V}_{\mathrm{BL}} \lambda \int_{0}^{\infty}\left(C_{\text {plasma }}\right)_{\text {i.v. }} d t}
$$




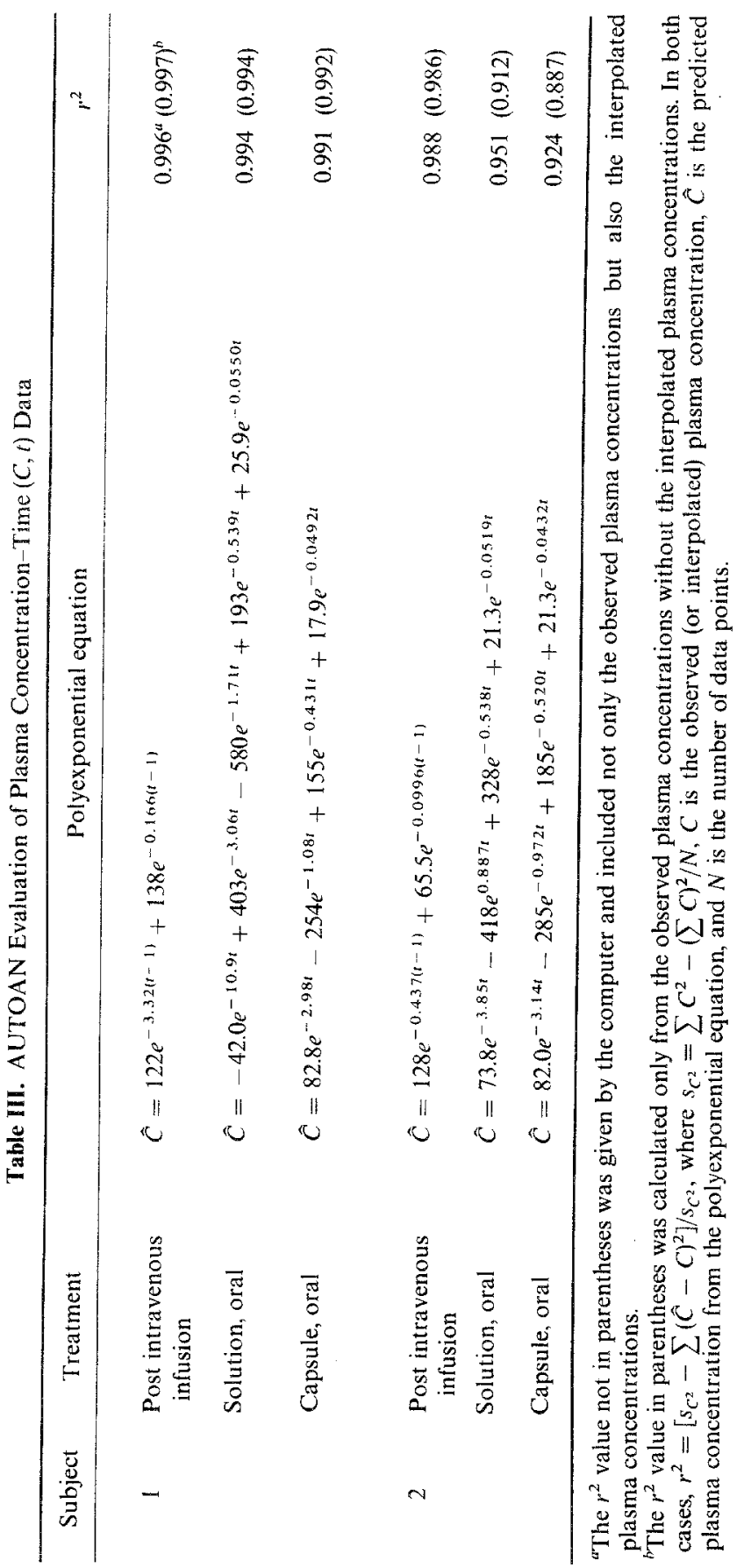


Table IV. Summary of Estimated Areas

\begin{tabular}{clcc} 
& & \multicolumn{2}{c}{ Estimated area 0 to $\propto(\mathrm{ng} / \mathrm{m}) \times \mathrm{hr})$} \\
\cline { 3 - 4 } Subject & \multicolumn{1}{c}{ Treatment } & From trapezoidal rule & $\begin{array}{c}\text { From integration of the }^{a} \\
\text { AUTOAN equation }\end{array}$ \\
\hline \multirow{2}{*}{1} & Intravenous infusion & 1181 & $1046^{c}$ \\
& Solution, oral & 579.2 & 617.2 \\
& Capsule, oral & 468.3 & 516.1 \\
2 & Intravenous infusion & 1062 & $1036^{c}$ \\
& Solution, oral & 557.3 & 568.0 \\
& Capsule, oral & 530.6 & 581.7 \\
\hline
\end{tabular}

${ }^{a}$ Area $=\int_{0}^{24} C d t+C_{24} / B$, where the integral was estimated by trapezoidal rule, $C_{24}$ is the observed plasma concentration at $24 \mathrm{hr}$, and $\beta=\left(\ln C_{12}-\ln C_{24}\right) / 12$ where the $C_{12}$ and $C_{24}$ are observed plasma concentrations at 12 and $24 \mathrm{hr}$, respectively, following intravenous infusion.

${ }^{h}$ Area obtained by integrating the polyexponential equation in Table III.

'The area obtained by trapezoidal rule in the interval 0 to $1 \mathrm{hr}$ was added to the area obtained by integrating the polyexponential equation given in Table III between limits of $1 \mathrm{hr}$ to $\infty$.

where $f_{m}$ represents the fraction of the dose which is metabolized in the liver, $\dot{V}_{\mathrm{BL}}$ is the liver blood flow rate, and $\lambda$ is the ratio of the concentration of drug in blood to the concentration of drug in plasma. Rowland (7) indicated that when the value of $\theta$ obtained from equation 1 is less than that obtained from equation 2 then either absorption is incomplete or metabolism occurs in the gut or during passage of the drug across the gut wall. Alternatively, he indicated that when the value of $\theta$ obtained with equation 1 is greater than that obtained with equation 2 then the concentration of drug in the hepatic portal vein following oral administration may be sufficiently high to saturate the metabolic enzymes.

The values of $\theta$ calculated with equations 1 and 2 are given in Table $\mathrm{V}$. The average value of 0.54 from equation 1 is only slightly greater than the value of 0.49 from equation 2 for subject 1 . The average value of 0.51 from equation 1 is essentially the same as the average value of 0.50 from equation 2 for subject 2 . Interestingly, as pointed out by one of the reviewers, a rectilinear plot of the plasma concentration data for subject 2 suggests a possible linearity for both the "during infusion" data and the postinfusion data from 1 to $4 \mathrm{hr}$. Yet for this subject the $\theta$ values obtained with equations 1 and 2 agree most closely. Also, other tests for saturation kinetics failed to support a saturation phenomenon.

The value of $f_{m}$ required for use of equation 2 was obtained by means of equation 3:

$$
f_{m}=1-f_{e}
$$


Pharmacokinetics of Diphenhydramine in Man

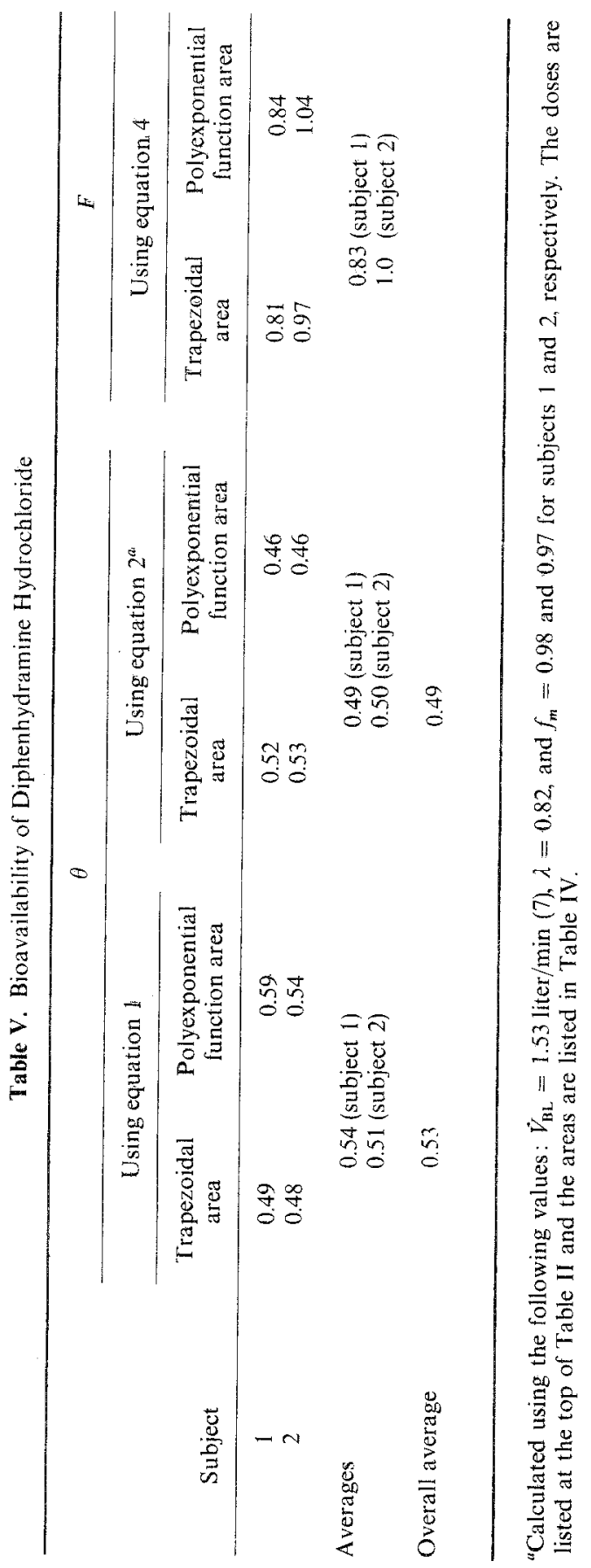


where $f_{e}$ is the fraction of the dose of drug which is excreted unchanged in the urine. These values, in percentage units, are given in Table II. The values in Table II, divided by 100 , average 0.03 and 0.02 for subjects 1 and 2 , respectively. The value of $\lambda$ was measured experimentally and found to average 0.82 for both subjects and to be independent of concentration.

\section{Efficiency of Absorption}

The bioavailability of diphenhydramine hydrochloride from Benadryl Kapseals relative to a solution of the drug given orally may be determined with equation 4 :

$$
F=\frac{(\text { dose })_{\text {soln }} \cdot \int_{0}^{\infty} C_{\text {cap. }} d t}{(\text { dose })_{\text {cap. }} \cdot \int_{0}^{\infty} C_{\text {soln. }} d t}
$$

Values of $F$ calculated by means of equation 4 are given in Table $\mathrm{V}$. The average values indicate that absorption from the capsule was only $83 \%$ relative to the solution in subject 1 but that absorption was complete in subject 2 .

\section{Plasma Protein Binding}

Table VI gives the percent unbound diphenhydramine at two concentrations. Since the unbound fraction appeared to be independent of concentration, a direct comparison of total plasma concentration (bound plus unbound) to assess bioavailability was justified. Also given in Table VI are the experimentally determined values of $\lambda$. As indicated above, these averaged 0.82 for both subjects.

\section{Correlation of Somnolescence with Plasma Concentration}

Both subjects went to sleep shortly after the 1-hr intravenous infusion ceased, but were only drowsy following the oral treatments. From the data in Table II, one can calculate that the ratio of the peak plasma concentration of diphenhydramine following intravenous administration to that following oral administration of the drug in solution was 3.7 for subject 1 and 2.8

Table VI. Diphenhydramine Plasma Binding and Blood/Plasma Distribution in Two Subjects

\begin{tabular}{cccccc}
\hline & \multicolumn{2}{c}{ Percent unbound } & & \multicolumn{2}{c}{ Blood/plasma } \\
\cline { 2 - 3 } \cline { 5 - 6 } Subject & $113 \mathrm{ng} / \mathrm{ml}$ & $1130 \mathrm{ng} / \mathrm{ml}$ & & $113 \mathrm{ng} / \mathrm{ml}$ & $904 \mathrm{ng} / \mathrm{ml}$ \\
\hline 1 & 1.5 & 1.3 & & 0.83 & 0.82 \\
2 & 1.8 & 1.7 & & 0.81 & 0.83 \\
\hline
\end{tabular}


for subject 2. These results suggest that when the plasma concentration of diphenhydramine exceeds about $70 \mathrm{ng} / \mathrm{ml}$ sleep may occur.

\section{Elimination Half-Life}

Data collected failed to delineate useful elimination half-lives of diphenhydramine in man. Apparent elimination half-lives are summarized in Table VII. These were calculated (a) from the observed plasma concentrations at 12 and $24 \mathrm{hr}$ and (b) by dividing the smallest rate constant of the polyexponential equations (given in Table III) into the natural logarithm of 2. The average of the eight half-lives obtained from the oral data is $15 \mathrm{hr}$, which agrees reasonably well with the value of $18 \mathrm{hr}$ reported by Glazko et al. (3). However, comparison with the values obtained from the two sets of intravenous infusion data indicates that these values derived from oral data are overestimates of the "true" elimination half-life, and probably indicate prolonged absorption of diphenhydramine following oral administration. It should also be noted from Table VII that the half-lives estimated from the smallest rate constants of the polyexponential equations fitted to the intravenous infusion data are smaller than those derived from the 12- and 24-hr plasma concentrations for both subjects. This suggests that the log linear phase did not begin until beyond $12 \mathrm{hr}$. Thus this analysis of admittedly inadequate data suggests that in these two subjects the "true" elimination half-life of diphenhydramine was probably in the 4- to 7-hr range. These data also suggest that estimation of elimination half-lives of diphenhydramine following either oral or intravenous administration requires measurement of plasma concentrations lower than $5 \mathrm{ng} / \mathrm{ml}$ and beyond $24 \mathrm{hr}$ after dosing.

Table VII. Apparent Elimination Half-Lives

\begin{tabular}{clcc}
\hline & & \multicolumn{2}{c}{ Apparent elimination half-life (hr) } \\
\cline { 3 - 4 } Subject & \multicolumn{1}{c}{ Treatment } & $\begin{array}{c}\text { From 12- and 24-hr } \\
\text { plasma levels }\end{array}$ & $\begin{array}{c}\text { From smallest rate constant } \\
\text { of polyexponential equations }\end{array}$ \\
\hline \multirow{2}{*}{1} & Intravenous infusion & 7.59 & 4.17 \\
& Solution, oral & 15.0 & 12.6 \\
& Capsule, oral & 14.1 & 14.1 \\
2 & Intravenous infusion & 10.4 & 6.96 \\
& Solution, oral & 13.3 & 13.4 \\
& Capsule, oral & 21.2 & 16.0 \\
\hline
\end{tabular}




\section{CONCLUSIONS}

Diphenhydramine exhibits a large first-pass effect, with about $50 \%$ metabolism occurring before the drug reaches the general circulation following oral administration. The drug administered in solution orally is apparently fully available to the hepatoportal system. When administered in capsule form orally, the drug was completely absorbed in one subject and about $83 \%$ absorbed in the other subject. Diphenhydramine is almost entirely biotransformed since less than $4 \%$ of the dose was excreted unchanged in the urine. Future pharmacokinetic investigations with this drug will require more intensive and more prolonged sampling than used in this pilot study and an assay method sensitive to at least $1 \mathrm{ng} / \mathrm{ml}$ of plasma.

\section{ACKNOWLEDGMENTS}

The authors are indebted to Anthony Glazko of Parke, Davis and Company for ${ }^{3} \mathrm{H}$-diphenhydramine hydrochloride and Allen J. Sedman of the University of Michigan for use of the Program AUTOAN.

\section{REFERENCES}

1. T. Sollman. A Mariual of Pharmacology and Its Application to Therapeutics and Toxicology, 8th ed., Saunders, Philadelphia, 1957, p. 559.

2. J. Hald. The excretion of diphenhydramine hydrochloride (dimethylaminoethyl benzyhydryl ether hydrochloride) in urine of rabbits and man. Acta Pharmacol. 3: 296-302 (1947).

3. A. J. Glazko. W. A. Dill, J. C. Drach, and T. Chang. Compilation of Symposta Papers, American Pharmaceutical Association, Washington D.C., 1970, pp. 339-340.

4. K. S. Albert, E. Sakmar, J. A. Morais, M. R. Hallmark, and J. G. Wagner. Determination of diphenhydramine in plasma by gas chromatography. Res. Commun. Chem. Pathol. Pharmacol. 7: 95-103 (1974).

5. AUTOAN, a time-sharing digital computer program, available from Publication Distribu= tion Service, 615 East University Avenue, Ann Arbor. Michigan 48106.

6. J. Fried and S. Zeitz. Curve fitting by spline and Akima methods: Possibility of interpolation errors and its suppression. Phys. Biol. Med. 18: 550-558 (1973).

7. M. Rowland. Influence of route of administration on drug availability. J. Pharm. Sci. 67: 70-74 (1972).

8. M. Gibaldi and S. Feldman. Route of administration and drug metabolism. Eur. J. Pharmacol. 19: 323-329 (1972).

9. G. Levy and R. Nagashima. Comparative pharmacokinetics of coumarin anticoagulants. VI. Effect of plasma protein binding on the distribution and elimination of bishydroxycoumarin by rats. J. Pharm. Sci. 58: 1001-1004 (1969). 